\title{
Perceived Supervisor's Support and Job Insecurity as Predictors of Employee Anxiety
}

\author{
Tochukwu M. Oguegbe, N.C. Etodike \& R. Ugwa \\ http://dx.doi./org/10.4314/ujah.v18i2.26
}

\section{Abstract}

Organisational stability is central to the strength of human development and organizational effectiveness which enables sustainable nation's development amidst global competitiveness. Hence this study examined perceived supervisor's support and job insecurity as predictors of employee anxiety. The study participants comprised of 211 workers (86 males) and (125) females drawn through systematic sampling from two local government areas. These participants are of the mean age of 35.22, standard deviation of 3.22 and age range of 19-56yrs. The study made use of three questionnaires namely-Symptoms Distress Check List (SCL-90R,) Perceived Supervisor's Support Scale and Job insecurity scale. The study adopted a correlation design with multiple linear regression as the statistics for data analysis. Findings indicated that the first hypothesis which stated that perceived supervisors' support will positively and significantly predict employee anxiety was rejected at $\alpha=.194, P>.05(N=$ 211). Findings also indicated that the second hypothesis which stated that job insecurity will positively and significantly predict employee anxiety was accepted at $\alpha=.007^{*}, \mathrm{P}<.05(\mathrm{~N}=211)$ and Findings also revealed that he third hypothesis which stated that supervisors' support and job insecurity will jointly predict employee anxiety was accepted at $r(1,211)=.002 *, P<.05$. Hence, findings were discussed and recommendations made.

Keywords: Employee anxiety, Supervisor's support, Job insecurity 


\section{Introduction}

\section{Background to the Study}

Anxiety is one of the critical issues for the managers of organizations as employee anxiety tend to contribute to organizational inefficiency. Employees are at the centre of every organization as such, the optimum performance of organizations depend heavily on the human capital and development of employees.

Nigeria as a developing country is witnessing great economic meltdown, consequently many organizations have witnessed reoccurring decline in productivity, efficiency and effectiveness in the workplace. These has led to a number of retrenchment evidenced in contemporary organizations due to alleged non commitment of workers to the goals of their organizations through a number of counter productive work behaviors which are inimical to the organizational effectiveness. These backgrounds have disposed many workers with the feeling of apprehension which can predispose inadequate performance of workers. This feeling of apprehension can be termed anxiety. Baggett, Saab \& Carter (1991) submitted that poor performance in organizations can be traced to a lot of problems most especially anxiety.

In the Diagnostic and Statistical Manual of Mental Disorders (DSM IV) published by the American Psychiatric Association , anxiety is defined as prior worrying towards danger or future misery along with dysphoria and physical symptoms of tension and the predicted source of danger might be internal or external (Khalatbari, 1983). Employee anxiety can generally be described as a feeling of fear which affects a worker in deferent facets of work life, for instance productivity level, interpersonal relationship 
etc. Anxiety is a negative emotion that has the capability to induce/influence behavior either negatively or positively (Uzonwanne, 2014). In contrast with anger, however, the action tendency for anxiety is avoidance and escape (Lazarus, 1999). People respond to stimuli that make them anxious by orienting themselves away from the stimuli and related consequences (Roth \& Cohen, 1986). Avoidance offers the opportunity to reduce stress and gradually recognize and deal with the threats that lead to the feelings of anxiety (Roth \& Cohen, 1986).

Brandes \& Bienvenu (2006) noted that anxiety is a person's tendency to become apprehensive before and during evaluative tasks especially under highly evaluative conditions with the result that the person's performance deteriorates. The root of this condition appears to be an inability to cope with the situation at hand. This inability is caused by a feeling of inadequacy, unpreparedness or over nervousness of making a mistake for the challenge or tasks and this negatively affects the person's ability to prepare and perform tasks that the challenge demands. Nevertheless, it is not enough to highlight that anxiety is detrimental to organizational process without emphasis on probable causes of this unavoidable problem. Researchers have attempted to explore the likely predictors of anxiety by focusing on several environmental determinants much of which has its root outside Nigeria. Hence the present study is an attempt to unearth certain psychological dispositions like supervisor support and job insecurity as predictors of employee anxiety within Nigerian context.

Supervisor support which can also be referred to as superior subordinate support is a term used to express the perceived value 
of acceptance appraisal, corrections, guidance which the superior shows toward his or her subordinate (Paille, Grima \& Bernardeau, 2013). It is also a reciprocal recognition of subordinates' value, efforts and sacrifices toward organizational processes. For employees perceived superior support refers to the 'degree to which supervisors value their contributions and care about their wellbeing (Eisenberger, 2002). Perceived supervisor support is an important input in the workplace. It has been shown that the perception of being supported by the supervisor enhances creativity in the workplace (Amabile, 2006), improves information sharing (Cabrera, 2006), and diminishes job anxiety (Greenglass, 1993). This is supported by studies like the work of Brandes \& Bievenu (2006) with 309 workers from a service industry in France which found that employees whose managers show more understanding and tolerance show less case of anxiety disorder than their counterparts whose managers give less room for understanding and consideration. In addition, $\mathrm{Ng}$ and Sorensen, (2008) contended that being supported by the supervisor has a positive impact on employees' attitudes in the workplace whereas being unsupportive may yield several negative outcomes such as anxiety.

Another factor of interest in determining employee anxiety could be associated with how secure the employees' job is guaranteed. This probably deals with so many problems associated with job insecurity. With job security an employee may not be settled on the job and this may the primary source of worry and anxiety. Job security has been defined as one's expectations about continuity in a job situation (Davy, Kinicki, \& Scheck, 1997). It includes desirable job features, such as promotion opportunities, current working conditions, and long-term career opportunities (Borg \& 
Elizur, 1992). On the other side, job insecurity refers to "an employee's negative reaction to the changes concerning their jobs" (Sverke \& Hellen, 2002). Job insecurity is characterized by powerlessness to maintain desired continuity in a threatened job situation (Greenhalgh \& Rosenblatt, 1984). According to Ashford, Lee, and Bobko (1989), lack of job security (i.e. job insecurity) leads to attitudinal reactions, such as intention to quit, reduced dedication, job stress, employee anxiety and reduced satisfaction.

Based on these obvious impacts of employee anxiety as outlined above, the present study is an attempt to investigate supervisor's support and job insecurity as predictors of employee anxiety.

In view of the conceptual model of this study, answers will be provided to the following research questions designed to aid the inquiry into this study.

i) Will perceived supervisor's support positively and significantly predict employees' anxiety?

ii) Will job insecurity positively and significantly predict employee anxiety?

iii) Will perceived supervisor's support and job insecurity jointly predict employee anxiety?

Based on the research questions, the study will test the following hypotheses that have been formulated to guide the study:

$\mathrm{H}^{1 \cdot}$ Perceived supervisor's support will positively and significantly predict employees' anxiety.

$\mathrm{H}^{2} \cdot \mathrm{Job}$ insecurity will positively and significantly predict employee anxiety.

$\mathrm{H}^{3}$ Perceived supervisor's support and job insecurity will jointly predict employee anxiety. 


\section{Method}

\section{Participants}

Participants in this study were two hundred and eleven (211) workers drawn through a simple random sampling two councilareas in Anambra State.The participants comprised of 159 females and 52 males within the age range of $19 y$ yrs to 56yrs with a mean age of $35.50 y$ rs and standard deviation of $3.22 \mathrm{yrs}$ for all participants.

\section{Instruments}

Three sets of instrument were used for the study - Symptoms Distress Check List (SCL-90R) by Derogatis and Lipman (1977), Perceived Supervisor's Support (Paille, Grima \& Bernardeau, (2013) and Job insecurity scale by Ashford, Lee \& Boko (1989). Other demographics were equally added to the instrument.

\section{Symptoms Distress Check List (SCL-90R)}

This is a 90-item questionnaire developed and validated by Derogatis and Lipman (1977). The researcher made use of 7-item subscale $\mathrm{G}$ measuring phobic anxiety from the $10 \mathrm{SCL}$ subscales scale. Derogatis \& Lipman (1977) originally validated the instrument and reported a cronbach's alpha coefficient between .77 and .90 for the subscales. However, it was validated in Nigeria by Erinoso (1996) who obtained a cronbach alpha coefficient of .75. For this study, test-retest reliability analysis with two weeks interval period between the first test and the second test was carried out with 51 participants and the result revealed a reliability coefficient of $\mathrm{r}=.90$. 


\section{Perceived Supervisor Support}

Perceived Supervisor Support was measured using a 4-item questionnaire developed by Paille, Grima \& Bernardeau (2013). The authors reported a cronbach's alpha $r=.94$. The scale was used to measure value and wellbeing between subordinates and their superiors. The response format was in 5-point likert scale of strongly agree (5) to strongly disagree (1). For its use in the present study, a test-retest reliability coefficient with 2 weeks interval was carried out by the researchers and an alpha reliability coefficient of .59 was obtained.

\section{Job Insecurity Scale}

It is made up of 7-items from 18-items originally developed by Ashford, Lee \& Boko (1989), they reported a cronbach's alpha of $r$ $=0.82$. Items were designed in a seven point response format from strongly disagree 1 to 7 strongly agree.

For its use in Nigeria, Omoroshemi (2005) validated it and obtained cronbach's validity of $=.70$ with coefficients reliability alpha coefficient of .65. However, for the present study, test-retest reliability analysis with two weeks interval period between the first test and the second test was carried out with 51 participants and the result revealed a reliability coefficient of $r=.64$.

\section{Design and Statistics}

The study being a survey adopted correlation design Hence, multiply regressions analysis was used for data analysis as the appropriate statistics 


\section{Results}

\section{Table 1:}

Table showing descriptive statistics, mean, standard deviations and number of participants for all variables.

\section{Descriptive Statistics}

\begin{tabular}{|l|r|r|r|}
\hline & \multicolumn{1}{|c|}{ Mean } & $\begin{array}{c}\text { Std. } \\
\text { Deviation }\end{array}$ & $\mathrm{N}$ \\
\hline Employee Anxiety & 27.5604 & 3.71435 & 211 \\
$\begin{array}{l}\text { Perceived Supervisor's } \\
\text { Support }\end{array}$ & 15.5314 & 1.50022 & 211 \\
Job Insecurity & 29.4783 & 4.57426 & 211 \\
$\begin{array}{l}\text { Perceived Supervisors' } \\
\text { Support \& Job } \\
\text { Insecurity }\end{array}$ & 45.0097 & 2.4532 & 211 \\
\hline
\end{tabular}

\section{Table 2:}

Summary table of multiple regressions analysis of relationships among perceived supervisor's support, job insecurity, perceived supervisor's support/job insecurity and employee anxiety

\section{Regressions Coefficients (a)}




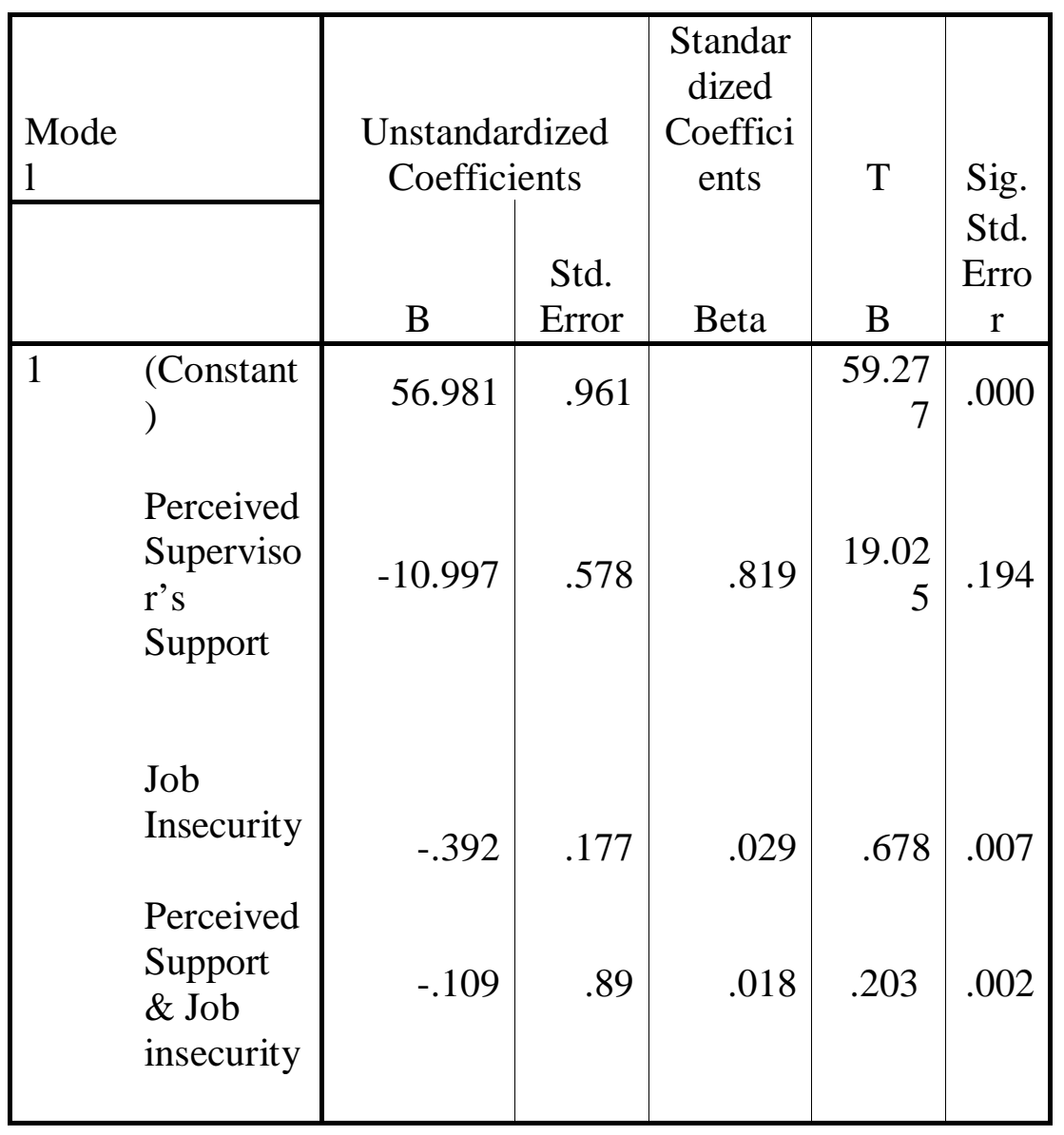

a Dependent Variable: Employee Anxiety 


\section{Hypothesis I}

$\mathrm{H}^{\mathrm{l}}$ : Perceived supervisor's support will positively and significantly predict employee anxiety.

Result tables as shown in $1 \& 2$ above showed that perceived supervisor's support did not have significant relationship with employee anxiety although it correlated positively with the construct; Correlations were not significant for the relationship between employee anxiety and supervisors' support at $\alpha=.194, \mathrm{P}$ $>.05(\mathrm{~N}=211)$. Therefore, hypothesis one which stated that perceived supervisor's support will positively and significantly predict employee anxiety is not confirmed and is thus rejected. This means that perceived supervisor support did not correlate positively and significantly with employee anxiety.

\section{Hypothesis II}

$\mathrm{H}^{2}$ : Job insecurity will positively and significantly predict employee anxiety.

From both result tables 1 \& 2 for descriptive statistics and regressions coefficients respectively, it has been shown that independently, only job insecurity positively and significantly predicted employee anxiety among workers. Correlations were significant for job insecurity scores in relation to employee anxiety at $\alpha=.007^{*}, \mathrm{P}<.05(\mathrm{~N}=211)$. Check .Therefore, hypothesis II which stated that perceived job insecurity will positively and significantly predict employee anxiety is confirmed and accepted. This means that job insecurity correlated positively and significantly with employee anxiety.

\section{Hypothesis III}

$\mathrm{H}^{3}$ : Perceived supervisor's support and job insecurity will jointly predict employee anxiety. 
Based on the table above, it has been observed that perceived supervisors' support and job insecurity jointly predicted employee anxiety among workers. Correlations were significant for perceived supervisors' support/job insecurity scores in relation to employee anxiety at $\alpha=.002 *, \mathrm{P}<.05(\mathrm{~N}=211)$. Therefore, hypothesis III which stated that perceived supervisor's support and job insecurity will jointly predict employee anxiety is confirmed and accepted. This means that supervisor's support and job insecurity jointly correlated positively and significantly with employee anxiety.

\section{Discussion and Conclusion}

This study examined perceived supervisor's support and job insecurity as predictors of employee anxiety. The aim of the study is to establish positive and significant relationship between the predictor variables (perceived supervisor's support and job insecurity) and the criterion variable (employee anxiety). In both the conceptual and theoretical model of the study, hypotheses tested in this study proposed that; both variables of the study will both independently and jointly predict employee anxiety. Data analyzed in descriptive and regressions tables as shown in presented in chapter four confirmed that only job insecurity independently predicted employee anxiety although both independent variables (perceived supervisor's support and job insecurity) jointly predicted the criterion variable - employee anxiety. Consequently, only hypotheses II \& III were confirmed and accepted as having positive and significant correlation with employee anxiety while perceived supervisors' support was rejected. 
The result of hypothesis I that stated that perceived supervisor's support will positively and significantly predict employee anxiety was rejected. This implies that there is no significant relationship between perceived supervisor's support and employee anxiety. This finding agrees with the position of Stamper (2003) that linked phobic anxiety to internal causes other than external causes of behaviour. The author was of the opinion that the primary cause of most chronic and generalized anxiety emanate from subjective perception and not necessarily objective causes such as human relationships as studied here as support. Stamper (2003) concluded that anxiety is more a problem of perception believe and internal evaluations of the human life, the environments and certain peculiar circumstances that arise from time to time in living the normal day to day life.

Also, this study supports the findings made earlier by Brown (2007) that anxiety stems from internalized feelings and evaluative of activities of life in relation to one's goal, aspirations and opportunities and how one is willing to accepted the changes brought about by these outcomes. The author above posits that anxiety may be self induced as a result of these evaluative processes rather than as a result of the problem itself.

Hypothesis II which stated that job insecurity will positively and significantly correlate employee anxiety was confirmed and accepted. The implication of this result is that the feelings of job insecurity have been identified as part of the causes and sources of employee anxiety. The result of the analysis of this hypothesis corresponds with by-products of job insecurity, a study carried out by Tyler (2003) to unravel the psychological problems associated with job insecurity. Among other things, the author found that 
chronic anxiety among workers whose jobs are not secured was significantly higher than those whose jobs were better secured. The author concluded that the presence of anxiety as triggered by the job insecurity heightened both the prevalence and severity of employee anxiety among other anxiety causative factors in the workplace. This finding of hypothesis two is consistent with the findings of Lee \& Olshfski, (2010) which revealed that a negative and significant relationship exists between commitment to the superior and intention to leave the organization. The authors opined that the desire to remain a member of an organization increases when attachment and loyalty to the superior are strong and these are boosted by job security which reduces employee anxiety about the outcome of their jobs.

Hypothesis III was also confirmed showing that a positive and significant relationship exists in the joint predictive influence between perceived supervisors support and job insecurity. In line with Brandes \& Bievenu (2006), who emphasized that the threat of job insecurity is the major source and cause of employee anxiety though not excluding other causative agents; also Cole, (2002); Lavelle, (2007); Schaninger \& Turnipseed, (2005), all found out the continuance commitment is encouraged by leader member exchange, a kind of supervisor's support. These compliment the findings of this current study in hypothesis II although, this clearly negates the findings of hypothesis I (perceived supervisor's support) whose independent predictive influences failed to reach significant proportions. Moreover, the findings can be accepted in view of the fact that predictive influences of perceived supervisor's support may be triggered in the presence of job insecurity threat and hence would combine to predict employee anxiety among other variables. 
Equally, the association of the variables (both independent and dependent) could further be explained in the light of the fact that perceived supervisors' support may also be part and parcel of job insecurity whereby employees that are not supported by their superiors may perceive it as job security threats. Whereas, other employees who are better supported by the organization and superiors may feel more cared for which is associated with job security.

\section{Conclusion}

In this study, the researchers investigated perceived supervisors' support and job insecurity as predictors of employee anxiety. In the analyses of the data gathered from the field, the following results were observed that: Perceived supervisor's support did not positively and significantly predict employee anxiety, consequently hypothesis I was rejected. Only job insecurity independently predicted employee anxiety, hence, job insecurity was confirmed and accepted as a predictor of employee anxiety among other organizational factors. Both independent variables (perceived supervisor's support and job insecurity) jointly predicted employee anxiety.

In view of the dangers of anxiety which may lead to serious health conditions including death of the person, the following are recommended for stakeholders:

Stakeholders as it concerns employers and owners of the organization should endeavour to define employee contract wherever, whenever and however they are engaged in the organization. This will inadvertently help them know their status in the organization and be able to plan ahead on their careers. Equally, these will also help reduce the tensions that may be 
associated with too rampart firing and hiring. It is expected that if an employee is meant to understand his or her faith in an organization, it will enable him or her accept the outcomes of his or her actions wherever they may be applicable.

On the part of the employees themselves, they are advised to understand that certain jobs by default are transitory in nature and as such may not be able to guarantee the expected long term employment to the disappointment of the employees who would expected otherwise. It is expected that if employees accept this dynamism in the organization higher incidences of employee related anxiety will significantly be reduced. Employees who are diagnosed with all forms of anxiety are also advised to regularly see their health professional to counsel them for treatment where appropriate.

Academically, it is recommended that upcoming studies find a way of measuring more directly supervisors' support in order to eliminate the error that may be contained in using perceived supervisor's support as a measure of supervisors' support. It is further suggested that new studies in this area should also focus on the unraveling which dimensions of job insecurity (severity or powerlessness) elicits more anxiety on the employees in order to throw more insights into the predictive influences of the variable.

Tochukwu M. Oguegbe

N.C. Etodike \& R. Ugwa

Nnamdi Azikiwe University, Awka toguegbe@yahoo.com 


\section{References}

Brandes M, \& Bienvenu Joseph, (2006). Personality and anxiety disorders; Current science Inc.

Brown, H D, (2007). Principles of language learning and teaching. Pearson education, Inc.

Hayes, J (2011). Dealing with anxiety and depression in the workplace. Journal of Training and Management 17(3),pp 234-243.

Klalatbari, J.(1983). A comparison of the effectiveness of cognitive behavior, Medicine, Cognitive and eclectic therapy in anxiety treatment. Doctoral Dissertation, Islamic Azad University, Tehran Science and Research Branch.

Lazarus ,R.S (1999). Stress and Emotion.: A New Synthesis. New York: Springer.

Roth, S \& Cohenb, L.J (1983). Approach, avoidance and coping with stress. American Journal of Psychology,(7):813-9.

Spielberger, D. (1983). Cognitive and emotional components of anxiety: literature review and a revised worry-emotionality scale, Journal of Educational Psychology, 73, 541-55.

Uzonwanne, F.C. (2014). Depression, anxiety and stress as correlates of organizational citizenship behavior among oil workers in Nigeria. European Journal of Globalization and Development Research, vol. 10, No.1. 